\title{
REVIEW
}

\section{VOIDING DYSFUNCTION AND URODYNAMIC ABNORMALITIES IN ELDERLY PATIENTS}

\author{
Cristiano M. Gomes, Sami Arap and Flávio E. Trigo-Rocha
}

GOMES CM et al. Voiding dysfunction and urodynamic abnormalities in elderly patients. Rev. Hosp. Clín. Fac. Med. S. Paulo 59(4):206-215, 2004.

Lower urinary tract dysfunction is a major cause of morbidity and decreased quality of life in elderly men and women. With the progressive aging of the population, it is important to understand common micturitional disorders that may occur in this population. Most urinary problems in the elderly are multifactorial in origin, demanding a comprehensive assessment of the lower urinary tract organs, functional impairments, and concurrent medical diseases. Urodynamics is a highly valuable tool in the investigation of elderly patients with lower urinary tract symptoms. Urodynamic tests are not always necessary, being indicated after excluding potentially reversible conditions outside the urinary tract that may be causing or contributing to the symptoms. Although urodynamic tests may reveal common diagnoses such as bladder outlet obstruction and stress urinary incontinence in the elderly population, findings such as detrusor overactivity and impaired detrusor contractility are common and have important prognostic and therapeutic implications. The purpose of this article is to describe common urologic problems in the elderly and review the indications for and clinical aspects of urodynamic studies in these conditions.

KEY WORDS: Aging. Bladder diseases. Urinary incontinence. Urodynamics.

Lower urinary tract dysfunction is a major cause of morbidity and decreased quality of life in elderly men and women. A number of studies have shown that the prevalence and annoyance of lower urinary tract symptoms (LUTS) increase with age. ${ }^{1-3}$ Urinary incontinence is the most common problem and is reported to affect $15 \%$ to $35 \%$ of community-dwelling individuals and $22 \%$ to $90 \%$ of those in nursing homes..$^{4-7}$ Despite these figures, many patients avoid discussing their problems with family members or health care professionals because of being too embarrassed or having low expectations of treatment. ${ }^{8,9}$ Many physicians also fail to investigate their patients' urinary problems. This situation is unfortunate, since with proper evaluation much can be done to alle- viate lower urinary tract symptoms. Moreover, complications may arise from neglected or improperly treated voiding dysfunction, including urinary tract infections, urinary retention, and even upper urinary tract damage.

The evaluation of elderly people with LUTS requires a thorough understanding of the physiology voiding as well as the pathophysiologic changes associated with aging. Most urinary problems in the elderly are multifactorial in origin, demanding a compre-

From the Division of Urology, Department of Surgery, Hospital das Clínicas, Faculty of Medicine, University of São Paulo - São Paulo/SP, Brazil.

E-mail: crismgomes@uol.com.br Received for publication on September 8, 2003. hensive assessment of the lower urinary tract organs, functional impairments, and concurrent medical diseases.

Even in the absence of pathological conditions, the lower urinary tract changes as the individual ages. Detrusor contractility as well as bladder capacity and the ability to postpone voiding decline in both sexes, whereas urinary flow decreases with age. Benign prostatic hyperplasia (BPH) causes the prostate to enlarge in most men, causing infravesical obstruction in nearly $50 \%$ of them. ${ }^{10,11}$ Other important changes observed in elderly men and women are an increased prevalence of involuntary bladder contractions and increased postvoid residual (PVR) volume. ${ }^{1,12}$ Urinary output during the nighttime is also in- 
creased even in the absence of congestive heart failure, $\mathrm{BPH}$, or other medical conditions. Increased nighttime urinary output in association with the sleep disorders that are common in the elderly result in a normal pattern of 1 or 2 episodes of nocturia in the majority of healthy individuals in this age group.

This article reviews the most common causes of voiding dysfunction in the elderly population, with special attention to the applications and findings of urodynamic studies. Technical aspects of the different urodynamic tests are not addressed in this chapter; the interested reader will find a number of specialized books and journal articles on that subject. ${ }^{13-16}$

\section{CLINICAL EVALUATION}

Geriatric patients may present with a broad spectrum of mental and physical disabilities, so the approach for each patient in treating LUTS must be individualized. In this patient population, the severity of comorbid conditions and the functional status are of utmost importance in defining the extent of investigation and the therapeutic goals.

A detailed clinical evaluation is the most important aspect in the assessment of elderly patients with LUTS. The evaluation has to characterize the voiding symptoms as well as the patient's general medical condition and mental status, enabling the physician to make a presumptive diagnosis and identify potentially reversible pathologic conditions.

A careful search for treatable causes of voiding problems that are unrelated to a urologic etiology is very important in the evaluation of elderly patients, particularly in those presenting with urinary incontinence. It has been demonstrated that a significant proportion of these patients have transient problems as a cause for their symptoms. These conditions have been included in the mnemonic DIAPPERS: delirium, infection, atrophic vaginitis, pharmaceuticals, psychological factors, excess urine output, restricted mobility, and stool impaction. ${ }^{17}$

The physical examination is an essential part of the evaluation of elderly patients. It can rule out or identify transient causes of voiding dysfunction and established urologic diseases as well as evaluating comorbid diseases and the functional ability. In women, the pelvic examination evaluates the existence of genital prolapse as well as atrophic vaginitis or urethritis. It is also important to determine the presence and severity of urinary incontinence with provocative stress testing, although this is not a highly sensitive and specific test for the diagnosis of genuine stress incontinence. ${ }^{18}$ The rectal examination is important for detecting prostate diseases in men as well as stool impaction and the integrity of the sacral innervation in both men and women. The presence of an enlarged prostate on rectal examination is consistent with bladder outlet obstruction and may warrant further investigation. However, it does not confirm or rule out BPH as the cause of prostate enlargement nor does it confirm the existence of bladder outlet obstruction. ${ }^{10}$

The minimum urological workup necessary for every patient presenting with lower urinary tract symptoms includes urinalysis, urine culture, pertinent blood tests, and PVR measurement. Ideally, a voiding diary of 2 to 3 days should be completed by the patient or caregiver to help to characterize the patient's usual fluid intake, voiding habits, and severity of incontinence. Radiological evaluation and cystoscopy may be necessary in some patients, particularly when hematuria is present, but the indications for these tests have to be appraised for each patient.

\section{URODYNAMICS}

Urodynamics is the dynamic study of transport, storage, and evacuation of urine by the urinary tract. It encompasses a variety of diagnostic tests, including uroflowmetry, cystometry, urethral pressure profile, pressure-flow studies, electromyography of the pelvic floor, and simultaneous radiographic visualization of the lower urinary tract (videourodynamics). These tests can be used alone or in combination to evaluate lower urinary tract function.

Urodynamic studies are considered a highly valuable tool for the evaluation of patients with lower urinary tract symptoms, and most experts agree that they provide the most accurate means of diagnosis of voiding problems. However, the indications for and the type of urodynamics necessary for each patient are controversial.

Elderly patients may present with LUTS that are secondary to changes in the lower urinary tract organs that occur as the individual ages and that are not pathological conditions. In addition, urinary symptoms in the elderly more often have multiple causes because of the higher prevalence of comorbid states such as previous urological surgeries, stroke, dementia, Parkinson's disease, and use of medications. Moreover, some urodynamic findings such as detrusor overactivity (DO) and detrusor hyperactivity with impaired contractility are frequent in the geriatric population and may mimic common urological problems like stress incontinence or bladder obstruction. For these reasons and because the symptoms are poor predictors of urodynamic diagnosis, some authors believe urodynamic studies should be used liberally in the eld- 
erly. ${ }^{19}$ In general, however, most urologists obtain a urodynamic evaluation only after ruling out reversible causes of voiding dysfunction and when the initial conservative treatment failed to improve the patient's symptoms and/ or the clinical assessment did not provide a diagnosis for the voiding problems. The authors believe urodynamic studies should be performed in elderly patients with significant lower urinary tract symptoms and coexisting neurologic disease, previous surgery on the lower urinary tract, high postvoid residual volumes, and whenever a surgical procedure is being considered.

Although urodynamics may be a valuable part of the clinical evaluation of a patient, it has to be analyzed in conjunction with all other information obtained from history and physical examination, voiding diaries, and radiographic and endoscopic exams. Ultimately, it is essential that urodynamic studies reproduce the patient's symptoms during the test to assure the validity of the urodynamic findings. This is not always easy for a number of reasons, particularly in the elderly. First, the test is performed in an unfriendly environment that includes the presence of the examiner and staff as well as the equipment. Moreover, the introduction of 1 or 2 catheters transurethrally into the bladder and another catheter into the rectum can be quite uncomfortable. Finally, a number of potential pitfalls may occur in a urodynamic study relating to fluid fill rate and temperature, patient position, catheter size, and presence of significant genital prolapse. Despite all of these factors, it has been shown that urodynamics is safe and reliable in the elderly population..$^{20,21}$

\section{A) UROFLOWMETRY}

Uroflowmetry is the measurement of urine flow over time and is an important test for the evaluation of the voiding phase of the micturition cycle.
It is a simple, objective, and noninvasive urodynamic study that may reveal an abnormal urinary pattern and can be used to identify patients who may need a more complex urodynamic test. However, since urinary flow is a function of both detrusor contractility and bladder outlet resistance (BOO), it does not establish a definite diagnosis. A normal flow rate may be present in a patient with significant infravesical obstruction, as long as the detrusor can compensate for the increased urethral resistance. Likewise, a weak urinary stream may be seen in a patient with severe outlet obstruction but also in a female patient with detrusor failure.
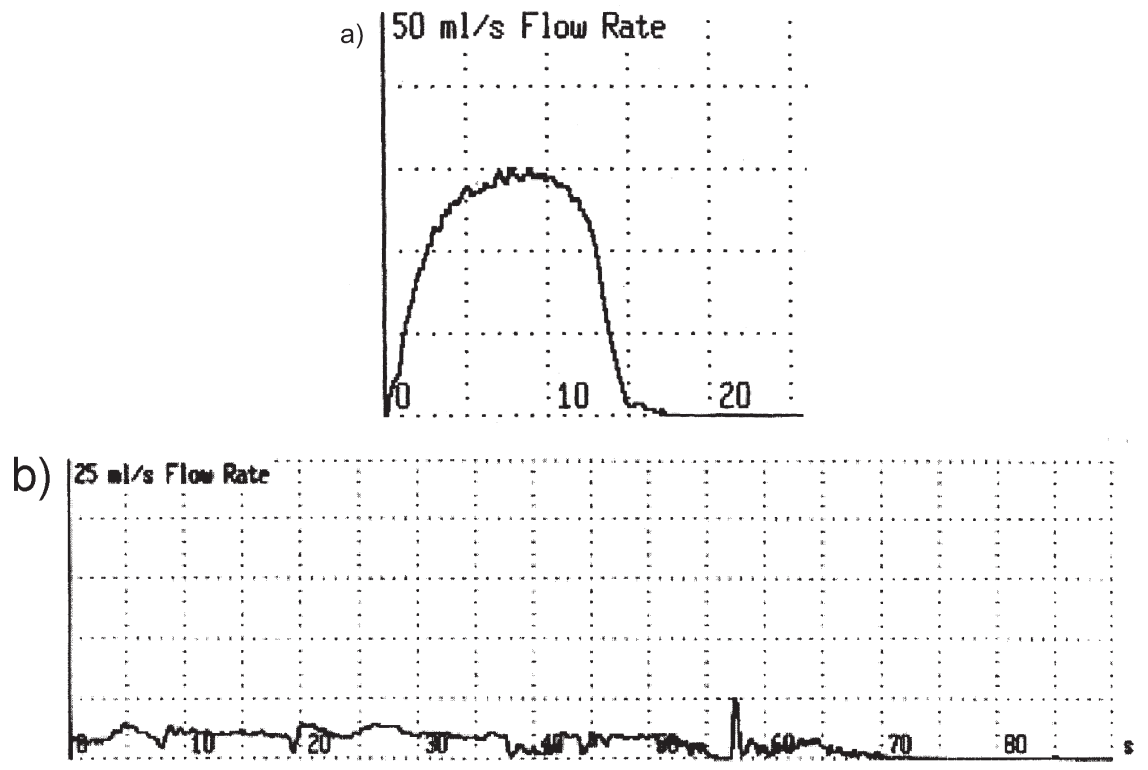

C)

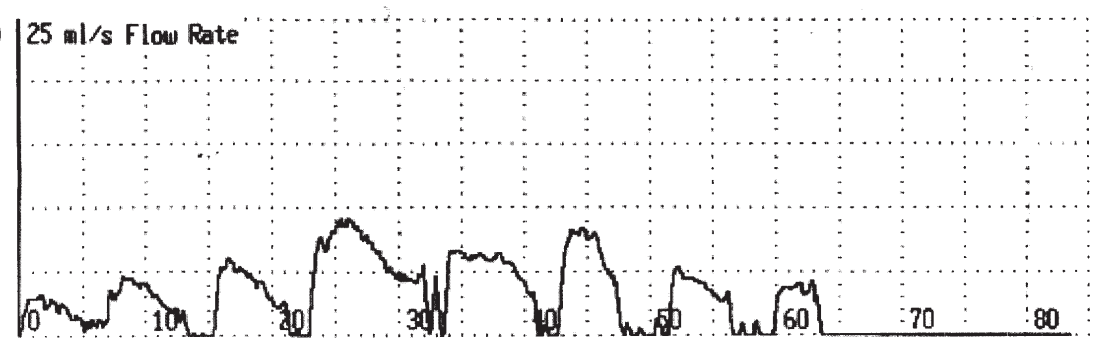

Figure 1 - Uroflowmetry. (a) Normal uroflow $\left(\mathrm{Q}_{\max }=30 \mathrm{~mL} / \mathrm{s}\right)$ in a 67 -year-old man presenting with filling symptoms 6 months after a transurethral resection of the prostate. His cystometrogram and pressure-flow studies are shown on Figures 2a and 3a, respectively; (b) Obstructive uroflow in a 75-year-old man with severe voiding symptoms. The flow pattern shows a sustained low flow rate that is consistent with but not diagnostic of bladder obstruction. Follow-up pressureflow study confirmed severe bladder obstruction (Figure 3b); (c) Interrupted uroflow due to abdominal straining in an 80-year-old diabetic man presenting with urge incontinence and obstructive symptoms and a high postvoid residual $(300 \mathrm{~mL})$. Follow-up pressure-flow study confirmed detrusor hyperactivity and impaired contractility (Figure 2b) 
tinence; (3) mental status may be limiting and (4) some patients have difficulty voiding in an unfriendly/unfamiliar place.

Despite its limitations in diagnosing, BOO uroflowmetry is a sensitive indicator of voiding dysfunction and can be used to distinguish patients who will promptly need further investigation from those who can be started on a treatment regimen and avoid extensive urodynamic testing. It can also be used in patients with a known $\mathrm{BOO}$ as a measure of progression of the disease or to determine the efficacy of treatment modalities that are expected to improve bladder emptying.

\section{B) RESIDUAL URINE MEASURE- MENT}

The postvoid residual urine (PVR) is the total volume of urine remaining in the bladder after voiding. It should be measured after an intentional void, since an incontinent patient may be able to partially suppress an involuntary detrusor contraction, resulting in an overestimation of the PVR. It can be accurately measured with a bladder catheter or by ultrasound and has a significant intraindividual variability in the elderly patient. ${ }^{23}$

Despite the fact that it does not correlate well with signs and symptoms of bladder obstruction and the inherent variability of the measurement, the PVR is an important part of the clinical investigation of elderly men and women. As with the urinary flow, the PVR is a function of both detrusor contractility and BOO and does not establish a definite diagnosis of obstruction or detrusor hypocontractility. However, it can be used to identify patients at risk for these conditions as well as to monitor the progression of the disease in patients with a known BOO. In general, a PVR of $>100 \mathrm{~mL}$ is considered high in a male elderly patient. Female patients tend to have lower PVR volumes than males. $^{23,24}$

\section{C) CYSTOMETRY}

Cystometry is a measure of the bladder's response to filling and evaluates the filling/reservoir phase of micturition. Many parameters should be studied during cystometry, including the bladder capacity, sensation, compliance, presence of involuntary detrusor contractions, and ability of the urethral sphincter to resist increases in abdominal pressure.

Although cystometry can be performed with different methodologies and technical variations, our review will present cystometry as a multichannel study, monitoring both vesical and abdominal pressure and allowing for automatic calculation of the detrusor pressure. However, since urodynamic setups are not available in many geriatric facilities, some authors have proposed a simple bedside evaluation using a urethral catheter connected to a $50 \mathrm{~mL}$ syringe that is used to fill the bladder under gravity. This method, also called eyeball urodynamics, may provide useful information on the bladder behavior during filling, but has obvious limitations compared to standard urodynamics regarding the evaluation of bladder contractility.

As noted before, many aspects of the physiology of micturition may change as a part of normal aging and may or may not play a pathogenic role in voiding dysfunction. A very common urodynamic finding in the elderly patient is DO, which is a major cause of urinary incontinence in elderly men and women (Figure 2a). ${ }^{1,25}$ However, DI can also be observed in nonsymptomatic elderly patients, occurring in up to $50 \%$ of these subjects. ${ }^{26}$ This fact emphasizes the importance of reproducing the patient's symptoms during the urodynamic test and also of analyzing its results in conjunction with all other information obtained from history and physical examination and other exams.
Detrusor overactivity in the geriatric population may be associated with impaired detrusor contractility, even in the absence of bladder obstruction. This condition, known as detrusor hyperactivity with impaired contractile function (DHIC), was described by Resnick and Yalla ${ }^{27}$ and may be a challenging cause of LUTS (Figure 2b). The pathogenic process that leads to DHIC is unknown. ${ }^{28}$ Clinically, patients with DHIC may be no different from patients with DI and normal contractility. In the urodynamics, patients with DHIC have higher postvoid residual urine and are not capable of generating effective detrusor contractions in the voiding phase of the study. No signs of bladder obstruction or sphincteric abnormalities are found in their urodynamic tests. The clinical implications associated with the diagnosis of DHIC are very important and emphasize the need of performing complex urodynamic studies in elderly patients with voiding dysfunction. DHIC must be distinguished from bladder outlet obstruction, which can also lead to high PVR and may be accompanied by DI in up to $50 \%$ of the patients. ${ }^{10}$ The treatment for the later may involve alpha-blocking agents or surgical correction of the obstruction, while patients with DHIC have a limited range of therapeutical options. DHIC can mimic a number of other clinical conditions, including urge and stress incontinence and sensory urgency. Again, the appropriate urodynamic diagnosis is very important for enabling counseling and better treatment selection. Patients with urge incontinence and normal detrusor contractility can be safely treated with bladder training and anticholinergic medications, while patients with DHIC are at high risk for developing urinary retention when they take anticholinergic drugs.

Stress incontinence is an important cause of urinary incontinence in elderly women and may be associated 
a)

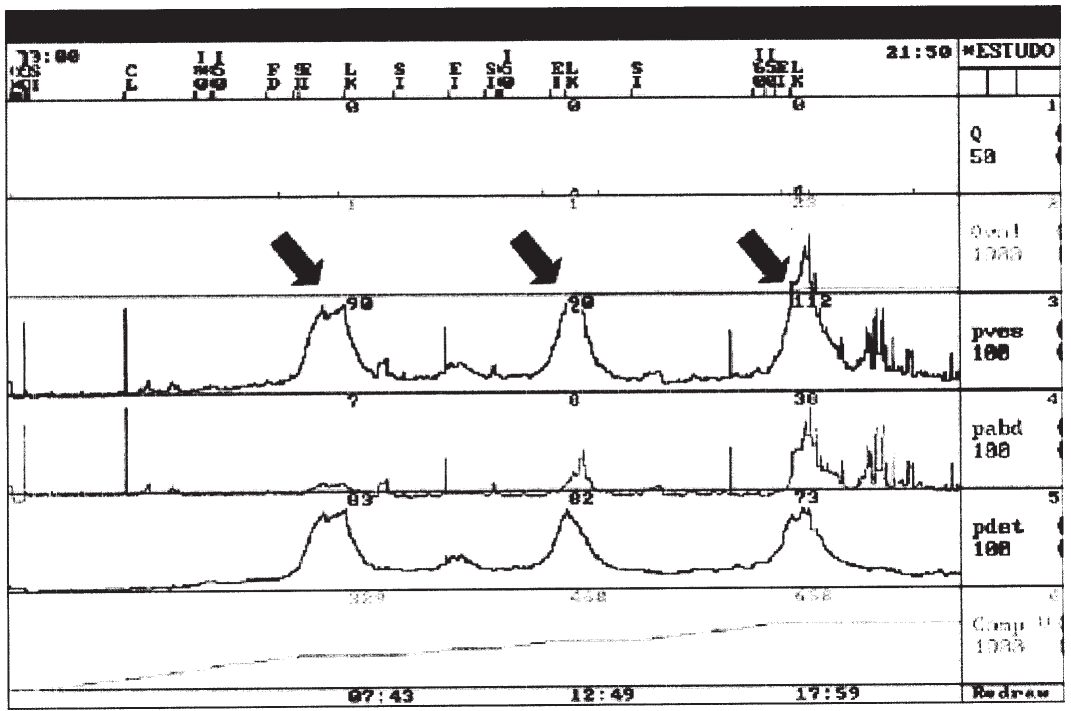

b)

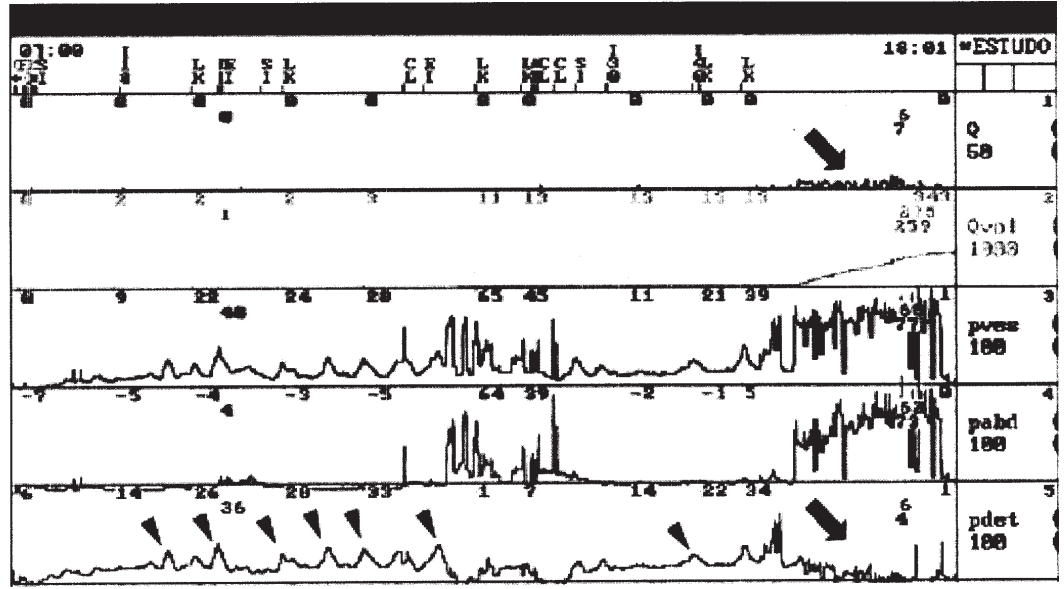

Figure 2 - Cystometric findings in the elderly. (a) Multichannel urodynamics tracing of a 67year-old man complaining of frequency, urgency, and urge incontinence 6 months after transurethral resection of the prostate, showing 3 episodes of detrusor overactivity accompanied by urge incontinence (arrows). His voiding study showed complete emptying with a high flow and low detrusor pressure (Figure 3a). The patient was started on anticholinergic medication and bladder training, with great clinical improvement; (b) An 80-year-old man complaining of the same symptoms of the previous patient. His pressure-flow study shows multiple lowpressure involuntary detrusor contractions during filling (arrow heads) and a low flow rate associated with abdominal straining and no detectable detrusor contraction in the voiding phase (arrows). Anticholinergic medications should be used cautiously in this patient because of the risk of precipitating urinary retention.

with urge incontinence (mixed urinary incontinence). ${ }^{1,25}$ In the male population, stress incontinence is uncommon and is usually secondary to prostate surgery and/or pelvic radiation or trauma. Elderly patients with suspected stress urinary incontinence should be tested with standard determination of the abdominal (or Valsalva) leak point pressure to determine the magnitude of urethral sphincter ing appropriate treatment, since it has been demonstrated that patients with significant intrinsic sphincter deficiency are not good candidates for pelvic floor rehabilitation and also have poor results after bladder neck suspension procedures. These patients may be better treated by a sling procedure or an injectable agent.

\section{D) PRESSURE-FLOW STUDIES OF MICTURITION}

Disorders of the voiding phase of the micturition cycle are very common in the elderly patient. As noted before, measurement of the urinary flow rate and postvoid residual volume can indicate the existence of an abnormality and even suggest a possible etiology for the problem, but its exact nature and severity can only be determined with the use of a more complex urodynamic test that simultaneously measures uroflow and detrusor pressure. This test, known as a pressureflow study, allows for the analysis of detrusor contractility and bladder outlet resistance (obstruction). Unless the patient has a significant functional disability or cognitive impairment, it is a simple test to perform in most patients undergoing a cystometry, since the only technical difference is that uroflowmetry is added to the study and the patient is required to void when his/her bladder is full.

Pressure-flow studies identify 3 fundamental voiding states: (1) low detrusor pressure with normal flow (unobstructed); (2) high detrusor pressure with low flow (obstructed); and (3) low detrusor pressure with low flow (poor detrusor contractility) (Figures 2b, 3a, and 3b). Occasional patients may have infravesical obstruction with a normal flow rate (Qmax $>15 \mathrm{~mL} / \mathrm{s})$ and a very high detrusor pressure, but this condition is not very common, and the patients are usually managed in the same fashion as those with a low flow and high detrusor pressure. 
a)

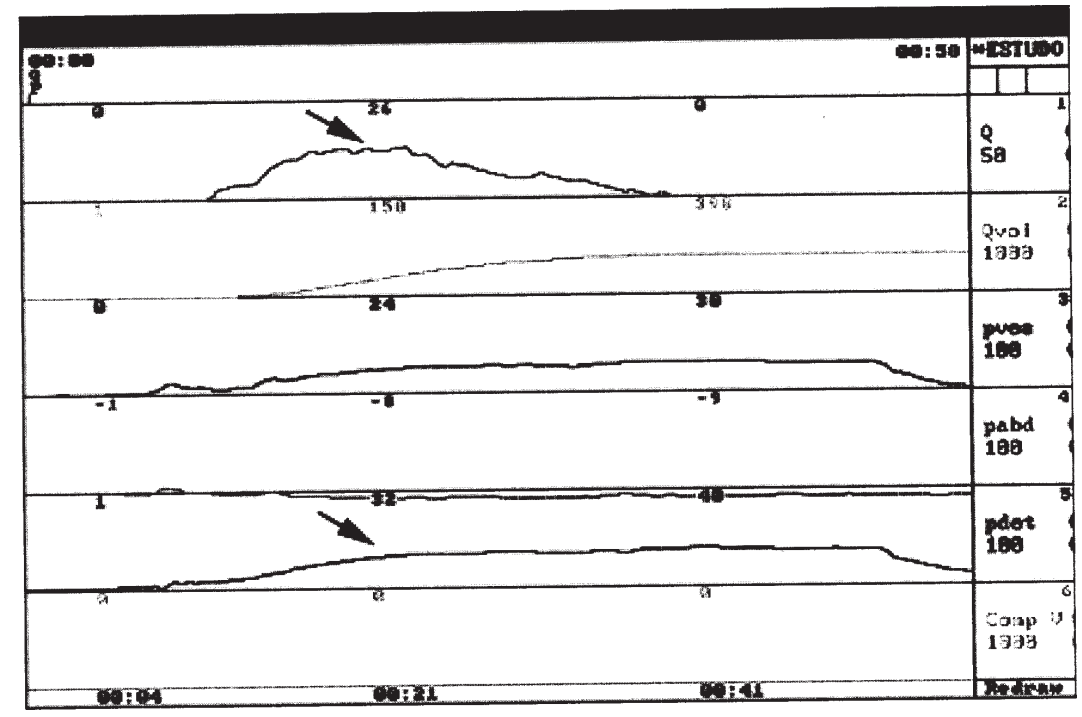

b)

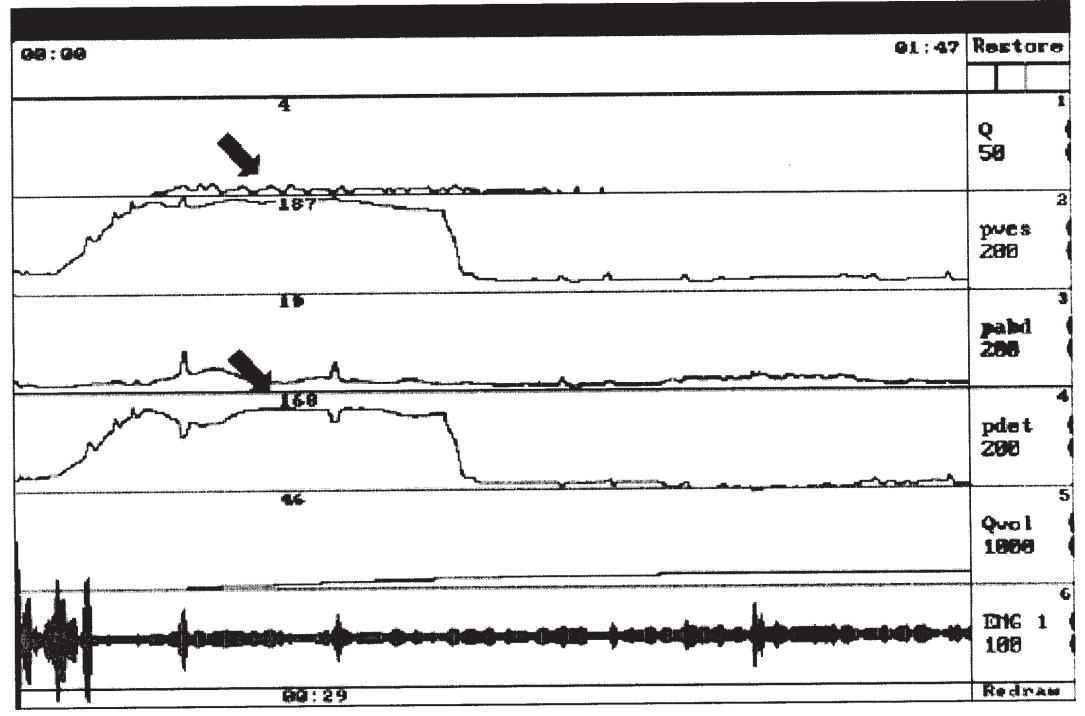

Figure 3 - Pressure-flow studies of micturition. (a) Voiding study of a 67-year-old man with unobstructed flow 6 months after transurethral resection of the prostate (cystometry showed in Figure 2a). The urodynamic tracings show a good maximum flow rate $\left(\mathrm{Q}_{\max }=26 \mathrm{~mL} / \mathrm{s}-\right.$ upper arrow) and a corresponding low detrusor pressure $\left(\mathrm{P}_{\text {detomax }}=32 \mathrm{~cm} \mathrm{H_{2 }} \mathrm{O}-\right.$ lower arrow); (b) $\mathrm{A}$ 75 -year-old man with a history of severe obstructive symptoms of decreased flow and hesitancy. His urodynamic study shows a high pressure-low flow pattern indicating bladder outlet

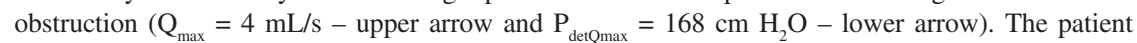
was treated with a transurethral resection of the prostate.

The importance of establishing these urodynamic diagnoses is obvious, since the prognosis and treatment alternatives for patients presenting with these conditions are completely different. In the elderly population, LUTS suggestive of BOO are commonly caused by pathophysiologic conditions other than bladder obstruction, and even women may have obstructive symptoms in the absence of bladder obstruction. ${ }^{28,30,31}$

Abnormal voiding can affect the bladder's ability to store and result in an abnormal cystometrogram. Detrusor overactivity and low bladder compliance are cystometric abnormalities that may be present in a significant number of patients with bladder outlet obstruction. ${ }^{32-34}$ They may improve in many patients after the relief of obstruction, but in the geriatric population, DO and urge incontinence may be the result of age-associated changes and not secondary to obstruction..$^{32,33}$ As a result, elderly patients who are potential candidates for prostatic surgery may have a worse prognosis, and DO is likely to persist following surgery to relieve BOO. ${ }^{35}$ This is also true for elderly patients with neurological diseases, such as Parkinson's disease, cerebrovascular accident, and multiple sclerosis, who are high-risk patients in term of having a poor outcome after prostate surgery and should be investigated with complete urodynamic studies before a decision is made to operate on these patients. ${ }^{36}$

Bladder outlet obstruction is an uncommon diagnosis in women. When present, this condition may be secondary to an anti-incontinence procedure, severe genital prolapse, or dysfunctional voiding. ${ }^{37}$ It is well known, however, that aging women may report voiding symptoms similar to agematched men despite the fact that they obviously do not have prostate-related voiding problems. Madersbacher et al. have compared age-related changes of urodynamic parameters in both sexes and have shown that age-associated urodynamic changes in both sexes are comparable for a number of parameters, including increase of postvoid residual volume and a decrease of peak flow rate, voided volume, and bladder capacity. ${ }^{31}$ With respect to DO, they observed an increase in men from $23.4 \%$ (40 to 60 years) to $46.7 \%$ (more than 80 years), whereas in women no significant age-related changes were present. These findings provide an explanation for the fact that aging women report comparable voiding symptoms as men and suggest a primary, non-sex-specific aging process of the urinary bladder.

\section{E) URETHRAL PRESSURE PROFILE (UPP)}

Different techniques of UPP have 
been used to study sphincteric function in patients with urinary incontinence and to evaluate patients with suspected obstruction. ${ }^{38,39}$ However, the value of UPP in these clinical settings is very controversial. There is poor correlation between UPP measurements and the presence of incontinence or continence in a number of clinical situations. ${ }^{40}$ Low urethral pressures, predicting incontinence, have been found in continent elderly patients. ${ }^{41}$ The authors do not routinely use UPP in the evaluation of patients with LUTS. Measurement of the leak point pressures has been shown to be a more reliable method of assessing sphincteric function and is also more practical, since it is a part of the filling phase of the study (cystometry). ${ }^{29}$

\section{F) VIDEOURODYNAMICS}

Videourodynamic studies consist of using a radiopaque contrast medium for urodynamics to allow simultaneous fluoroscopic visualization of the bladder and urethra during the filling and emptying phases. This technique is considered the most complete and pre-

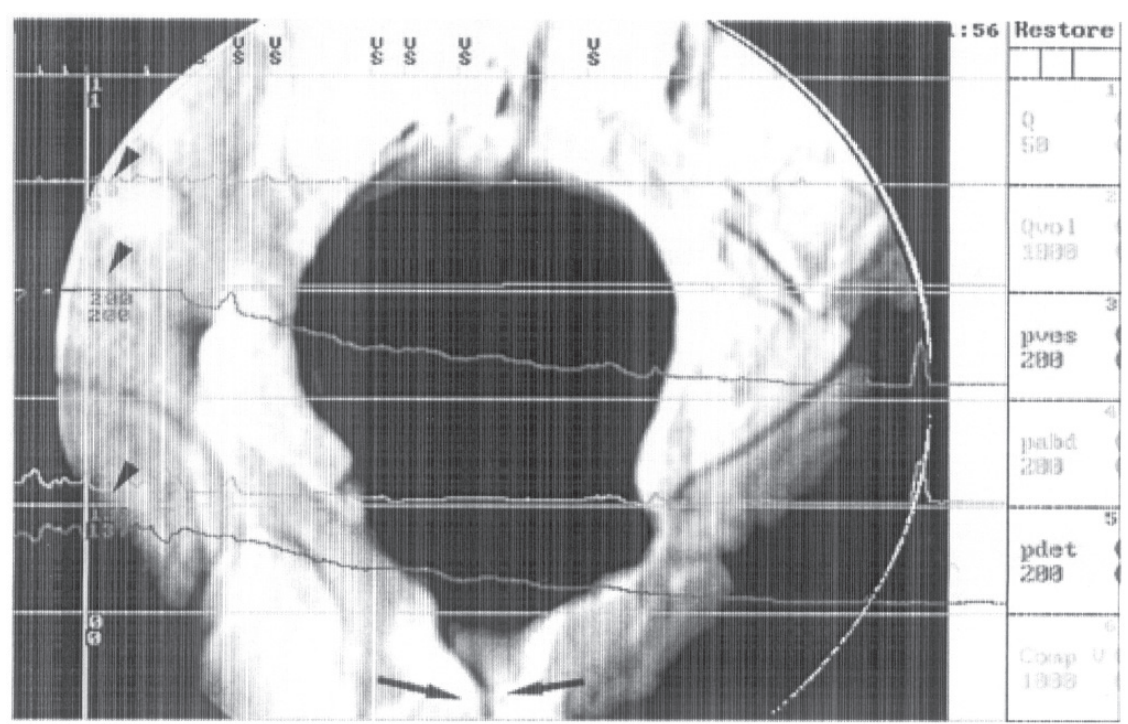

Figure 4 -Videourodynamics. A 64-year-old woman complaining of hesitancy, low flow, and frequency 2 years after a transvaginal anti-incontinence surgery and 1 year after a cerebrovascular accident. The voiding study demonstrates a high pressure-low flow pattern (arrow heads), and the level of obstruction is shown at the mid-urethra (arrows). The patient underwent a urethrolysis procedure with great improvement of the obstructive symptoms. hematuria, and urinary tract infection. Of these complications, urinary tract infection has been investigated in more detail. Studies indicate a low rate of significant bacteriuria varying from $1 \%$ to $4 \%$ in women ${ }^{42-44}$ and from $2 \%$ to $6 \%$ in men occur after urodynamic studies. ${ }^{45-47}$ Cases of urinary tract infections are usually mild but on rare occasions may require hospitalization. It is not clear whether the presence of infravesical obstruction and high postvoid residual urine is associated with an increased risk of urinary infection after urodynamics. ${ }^{46,48}$

It is important to assure that the patient has sterile urine before the exam. The benefit of antibiotic prophylaxis in patients without a history of urinary tract infections is not clear, but most urologists recommend the use of a quinolone starting in the day of the test for a period of 1 to 5 days.

Gross hematuria and urinary retention are rarely seen as a complication of urodynamics in women and may occur in $3 \%$ to $4 \%$ of male patients. ${ }^{46}$ Obstructed patients have a higher risk for developing urinary retention.

Although complications after urodynamics are uncommon and usually mild, the potential morbidity must be considered and discussed with the patient before performing urodynamic testing.

\section{CONCLUSIONS}

Urodynamics is a highly valuable tool in the investigation of elderly patients with LUTS with or without incontinence. Incontinence and other LUTS may be a manifestation of a subacute or reversible process within or outside of the lower urinary tract, and may be effectively treated in most instances. Urodynamic tests are not always necessary, being indicated after excluding potentially reversible conditions outside the urinary tract that may be caus- 
ing or contributing to the symptoms. The potential discomfort and morbidity that may be caused by the test should also be considered in the decision to obtain the exam. The initial evaluation of an incontinent geriatric patient includes a targeted history and physical examination, urinalysis, voiding diaries, and simple tests of lower urinary tract function like uroflowmetry and PVR. This evaluation should allow the clinician to identify patients who will need more complex urodynamic tests including those for whom a presumptive diagnosis cannot be made and those who failed initial conservative treatment. Although complications after urodynamics are uncommon and usually mild, the potential morbidity must be considered and discussed with the patient before performing urodynamic testing.
Urodynamic findings in the elderly may include common diagnoses like bladder outlet obstruction and stress urinary incontinence. However, urologic problems often coexist in the elderly, and conditions such as DO and impaired detrusor contractility are common. The identification of these conditions is necessary to assure accurate prognostic counseling and treatment selection.

\section{RESUMO}

GOMES CM e col. Distúrbios miccionais e anormalidades urodinâmicas em pacientes idosos - Rev. Hosp. Clín. Fac. Med. S. Paulo 59(4): 206-215, 2004.

Disfunções do trato urinário inferior são uma causa importante de morbidade e diminuição da qualidade de vida em homens e mulheres idosos. Com o envelhecimento progressivo da população, é importante compreender os distúrbios miccionais mais comuns nesta população. A maioria dos problemas miccionais em homens idosos tem origem multifatorial, requerendo uma avaliação ampla dos órgãos do trato urinário inferior, da capacidade funcional e neurológica dos pacientes e dos problemas clínicos coexistentes. A avaliação urodinâmica é uma ferramenta importante na investigação de pacientes idosos com sintomas do trato urinário inferior. Ela não é necessária em todos os casos e só deve ser indicada após a exclusão de problemas não urológicos e potencialmente reversíveis que poderiam causar ou contribuir para os sintomas miccionais. Embora os exames urodinâmicos possam revelar diagnósticos comuns como obstrução vesical ou incontinência urinária de esforço, na população idosa é frequiente a ocorrência de achados como hiperatividade detrusora e falência da contratilidade vesical, com implicações prognósticas e terapêuticas importantes. O objetivo deste artigo é descrever os problemas urológicos mais comuns nos idosos e discutir as indicações e características dos exames urodinâmicos nestas condições.

\section{UNITERMOS: Envelhecimento. Doenças da bexiga. Incontinência urinária. Urodinâmica.}

\section{REFERENCES}

1. Hampel C, Wienhold D, Benken N, Eggersmann C, Thuroff JW. Definition of overactive bladder and epidemiology of urinary incontinence. Urology 1997;50(6A):4-14.

2. Haidinger G, Madersbacher S, Waldhoer T, Lunglmayr G, Vutuc C. The prevalence of lower urinary tract symptoms in Austrian males and associations with sociodemographic variables. Eur J Epidemiol 1999;15(8):717-22.

3. Koskimaki J, Hakama M, Huhtala H, Tammela TL. Prevalence of lower urinary tract symptoms in Finnish men: a populationbased study. Br J Urol 1998;81(3):364-9.

4. Fantl JA, Newman DK, Colling J. Urinary incontinence in adults: Acute and chronic management. Clinical Practice Guideline 1996. Rockville, MD: U.S. Department of Health and Human Services. Clinical Practice Guidelines, Public Health Service, Agency for Health Care Policy and Research.

5. Schmidbauer J, Temml C, Schatzl G, Haidinger G, Madersbacher S. Risk factors for urinary incontinence in both sexes. Analysis of a health screening project. Eur Urol 2001;39(5):565-70.
6. Chiarelli P, Brown WJ. Leaking urine in Australian women: prevalence and associated conditions. Women Health 1999;29(1):1-13.

7. Damian J, Martin-Moreno JM, Lobo F, Bonache J, Cervino J, Redondo-Marquez L. Prevalence of urinary incontinence among Spanish older people living at home. Eur Urol 1998;34(4):333-8.

8. Rovner ES, Gomes CM, Trigo-Rocha FE, Arap S, Wein AJ. Evaluation and treatment of the overactive bladder. Rev Hosp Clin 2002;57(1):39-48.

9. Roberts RO, Jacobsen SJ, Rhodes T, Reilly WT, Girman CJ, Talley $\mathrm{NJ}$, et al. Urinary incontinence in a community-based cohort: prevalence and healthcare-seeking. J Am Geriatr Soc 1998;46(4):467-72.

10. Gomes CM, Trigo-Rocha F, Arap MA, Arap S. Bladder outlet obstruction and urodynamic evaluation in patients with benign prostatic hyperplasia. Braz J Urol 2001;27(6):575-88. 
Voiding dysfunction and urodynamic abnormalities in elderly patients Gomes CM et al.

11. Resnick NM, Elbadawi A, Yalla SV. Age and the lower urinary tract: What is normal? Neurourol Urodyn 1995;14(6):577-9.

12. Homma Y, Imajo C, Takahashi S, Kawabe K, Aso Y. Urinary symptoms and urodynamics in a normal elderly population. Scand J Urol Nephrol 1994;157(Suppl):27-30.

13. Mundy AR, Stephenson TP \& Wein AJ. Urodynamics: Principles, practice and application. Edinburgh, Churchill Livingstone, 1994.

14. Nitti VW. Practical Urodynamics. Philadelphia, Pennsylvania, W.B. Saunders Company, 1998.

15. Boone, TB. Urodynamics I. Urol.Clin.North Am. 23(2), 171336. 1996.

16. Boone, TB. Urodynamics II. Urol.Clin.North Am. 23(3), 337520. 1996.

17. Resnick NM. Urinary incontinence in the elderly. Med Grand Rounds 1984;3:281-90.

18. Cundiff GW, Harris RL, Coates KW, Bump RC. Clinical predictors of urinary incontinence in women. American Journal of Obstetrics \& Gynecology 1997;177(2):262-6.

19. Castleden CM, Duffin HM, Asher MJ. Clinical and urodynamic studies in 100 elderly incontinent patients. Br Med J (Clin Res Ed) $1981 ; 282(6270): 1103-5$.

20. Griffiths DJ, McCracken PN, Harrison GM, Gormley EA. Characteristics of urinary incontinence in elderly patients studied by 24 -hour monitoring and urodynamic testing. Age Ageing 1992;21(3):195-201.

21. Tammela TL, Schafer W, Barrett DM, Abrams P, Hedlund H, Rollema HJ, et al. benign prostatic enlargement. Finasteride Urodynamics Study Group. Repeated pressure-flow studies in the evaluation of bladder outlet obstruction due to Neurourol Urodyn 1999;18(1):17-24.

22. Drach GW, Layton TN, Binard WJ. Male peak urinary flow rate: relationships to volume voided and age. J Urol $1979 ; 122(2): 210-4$.

23. Griffiths DJ, Harrison G, Moore K, et al. Variability of post-void residual urine volume in the elderly. Urol Res 1996;24(1):236.

24. Bonde HV, Sejr T, Erdmann L, Meyhoff HH, Lendorf A, Rosenkilde P, et al. Residual urine in 75-year-old men and women. A normative population study. Scand J Urol Nephrol 1996;30(2):89-91.

25. Payne CK. Epidemiology, pathophysiology, and evaluation of urinary incontinence and overactive bladder. Urology 1998;51(2A Suppl):3-10.

26. Andersen JT, Jacobsen O, Worm-Petersen J, Hald T. Bladder function in healthy elderly males. Scand J Urol Nephrol 1978;12(2):123-7.

27. Resnick NM, Yalla SV. Detrusor hyperactivity with impaired contractile function. An unrecognized but common cause of incontinence in elderly patients. JAMA 1987;257(22):307681.
28. Griffiths DJ, McCracken PN, Harrison GM, Gormley EA, Moore $\mathrm{KN}$. Urge incontinence and impaired detrusor contractility in the elderly. Neurourol Urodyn 2002;21(2):126-31.

29. McGuire EJ, Cespedes RD, O'Connell HE. Leak-point pressures. Urol Clin North Am 1996;23(2):253-62.

30. Madersbacher S, Pycha A, Klingler CH, Schatzl G, Marberger M. The International Prostate Symptom score in both sexes: a urodynamics-based comparison. Neurourol Urodyn 1999;18(3):173-82.

31. Madersbacher S, Pycha A, Schatzl G, Mian C, Klingler CH, Marberger M. The aging lower urinary tract: a comparative urodynamic study of men and women. Urology 1998;51(2):206-12.

32. Abrams PH, Farrar DJ, Turner-Warwick RT, Whiteside CG, Feneley RC. The results of prostatectomy: a symptomatic and urodynamic analysis of 152 patients. J Urol 1979;121(5):64042.

33. Madersbacher S, Pycha A, Klingler CH, Mian C, Djavan B, Stulnig $\mathrm{T}$, et al. Interrelationships of bladder compliance with age, detrusor instability, and obstruction in elderly men with lower urinary tract symptoms [see comments]. Neurourol Urodyn 1999;18(1):3-15.

34. Rosier PF, de la Rosette JJ, Wijkstra H, Van Kerrebroeck PE, Debruyne FM. Is detrusor instability in elderly males related to the grade of obstruction? Neurourol Urodyn $1995 ; 14(6): 625-33$.

35. Gormley EA, Griffiths DJ, McCracken PN, Harrison GM, McPhee MS. Effect of transurethral resection of the prostate on detrusor instability and urge incontinence in elderly males. Neurourol Urodyn 1993;12(5):445-53.

36. Cockett AT, Khoury S, Aso Y. Proceedings of the 2nd International Consultation on Benign Prostatic Hyperplasia (BPH). Scientific Communications International Ltd., 1993.

37. Nitti VW, Tu LM, Gitlin J. Diagnosing bladder outlet obstruction in women. J Urol 1999;161(5):1535-40.

38. Constantinou CE, Christensen LL. Urethral pressures in the study of female incontinence. In: RAZ S, (Ed.) - Female Urology. Philadelphia, W.B. Saunders, 1996.p.115-31.

39. Sullivan MP, Comiter CV, Yalla SV. Micturitional urethral pressure profilometry. Urol Clin North Am 1996;23(2):263-278.

40. Nager CW, Schulz JA, Stanton SL, Monga A. Correlation of urethral closure pressure, leak-point pressure and incontinence severity measures. Int Urogynecol J Pelvic Floor Dysfunct 2001;12(6):395-400.

41. Diokno AC, Normolle DP, Brown MB, Herzog AR. Urodynamic tests for female geriatric urinary incontinence. Urology 1990;36(5):431-39.

42. Brostrom S, Jennum P, Lose G. Morbidity of urodynamic investigation in healthy women. Int Urogynecol J Pelvic Floor Dysfunct 2002;13(3):182-4.

43. Bombieri L, Dance DA, Rienhardt GW, Waterfield A, Freeman RM. Urinary tract infection after urodynamic studies in women: incidence and natural history. BJU Int 1999;83(4):392-5. 
REV. HOSP. CLÍN. FAC. MED. S. PAULO 59(4):206-215, 2004

44. Bergman A, McCarthy TA. Antibiotic prophylaxis after instrumentation for urodynamic testing. Br J Urol 1983; 55(5):568-9.

45. Carter PG, Lewis $P$, Abrams P. Urodynamic morbidity and dysuria prophylaxis. Br J Urol 1991;67(1):40-1.

46. Klingler HC, Madersbacher S, Djavan B, Schatzl G, Marberger M, Schmidbauer CP. Morbidity of the evaluation of the lower urinary tract with transurethral multichannel pressure-flow studies. J Urol 1998;159(1):191-4.
Voiding dysfunction and urodynamic abnormalities in elderly patients

Gomes CM et al.

47. Turck M, Goffe B, Petersdorf RG. The urethral catheter and urinary tract infection. J Urol 1962;88:834-7.

48. Hinman Jr F, Cox CE. The voiding vesical defense mechanism: the mathematical effect of residual urine, voiding interval and volume on bacteriuria. J Urol 1966;96(4):491-8. 